\title{
Iron Man to the rescue?
}

\author{
Frank A. Baciewicz, Jr, MD
}

\footnotetext{
From the Division of Cardiothoracic Surgery, Michael and Marian Ilitch Department of Surgery, Wayne State University School of Medicine, Detroit, Mich.

No funding was provided.

Disclosures: Author has nothing to disclose with regard to commercial support.

Received for publication July 13, 2018; accepted for publication July 16, 2018; available ahead of print Aug 21, 2018 .

Address for reprints: Frank A. Baciewicz, Jr, MD, Division of Cardiothoracic Surgery, Michael and Marian Ilitch Department of Surgery, Wayne State University School of Medicine, Harper Hospital, 3990 John R, Detroit, MI 48201 (E-mail: fbaciewi@dmc.org).

J Thorac Cardiovasc Surg 2019;157:298-9

$0022-5223 / \$ 36.00$

Copyright $(2) 2018$ by The American Association for Thoracic Surgery

https://doi.org/10.1016/j.jtcvs.2018.07.028
}

Recent efforts have been devoted to decreasing cardiac surgical costs by avoiding postoperative complications, including renal insufficiency/dialysis. This complication occurs in $10 \%$ to $15 \%$ of postoperative patients, carries a high financial burden, ${ }^{1}$ and is associated with increased short- and long-term mortality. ${ }^{2,3}$

Attempts to predict postoperative renal failure have populated the literature. Albert and coauthors ${ }^{4}$ have shown that urinary biomarkers, including neutrophil gelatinaseassociated lipocalin, midkine, and interleukin 6 , can predict postoperative renal failure. Similarly, Moledina and associates ${ }^{5}$ demonstrated that plasma monocyte chemotactic protein-1 increases are associated with postoperative renal insufficiency. Both studies note that serum creatinine is a poor marker for predicting postoperative renal failure.

It is well established that hemolysis during cardiopulmonary bypass (CPB) increases free plasma iron, which is associated with acute kidney injury. Hepcidin-25, an iron scavenger from hepatocytes, intestinal cells, and erythrocytes, ${ }^{6}$ has been shown to decrease postoperative renal failure. Free plasma iron promotes ferroptosis or postoperative renal tubular cell death through lipid peroxidation. Reducing iron levels during $\mathrm{CPB}$ thus may reduce risk of kidney dysfunction and improve outcomes.

Against this background, Choi and colleagues ${ }^{7}$ from the University of Manitoba prospectively measured intraoperative iron-binding protein ferritin, transferrin saturation, and postoperative day 1 levels of hepcidin-25 in patients having cardiac surgery. They compared ferritin, transferrin saturation, and hepcidin-25 values in acute kidney injury (AKI, defined by standard criteria) and non-AKI cohorts. Their investigation found that serum ferritin was inversely related to postoperative AKI. In other words, the higher the intraoperative serum ferritin (the less free iron), the less likelihood of renal insufficiency. Similarly, the higher the intraoperative transferrin saturation (iron transport protein), the lower probability of postoperative AKI. If postoperative urine showed elevated levels of hepcidin-25 (iron renal insufficiency. failure.

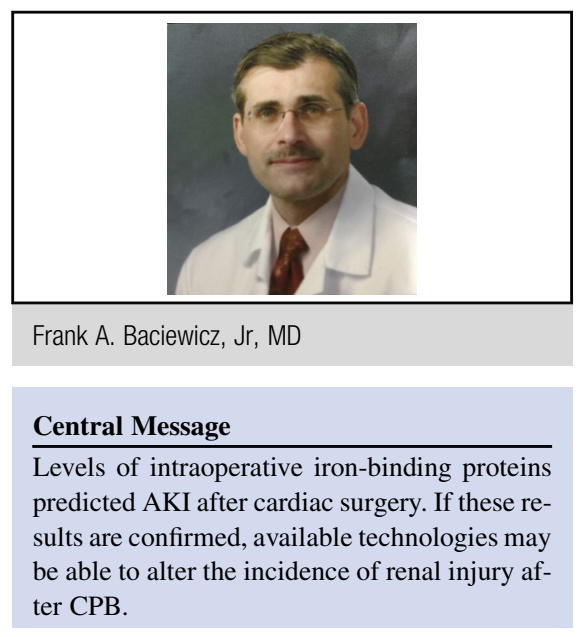

See Article page 287.

scavenger), then postoperative renal failure was less likely. Hepcidin-25 also inhibits ferroptosis, which requires iron, so a high level would be expected in the non-AKI group. The common thread is that lower serum iron or higher levels of an iron scavenger are associated with lower probability of

These findings support clinical experience that patients undergoing cardiac surgery who have a low hemoglobin and are receiving intraoperative blood transfusion typically demonstrate free serum hemoglobin and secondary AKI. These iron-binding proteins gauge different aspects of the iron regulation process during cardiopulmonary bypass. When these data points were added to the Thakar clinical score $^{8}$ (a predictor of postoperative AKI), the resulting model was a more accurate predictor of postoperative renal

The study did not measure ferritin or transferrin saturation other than before bypass and after 1 hour of CPB and did not measure hepcidin-25 intraoperatively. Additional data collection during cardiopulmonary bypass and postoperatively may better elucidate the intraoperative iron story.

The patients studied had low Thakar scores and consequently a low probability of postoperative renal failure. In addition, there were only 40 patients with AKI in the study. If these results are reproducible in high-risk patients and larger cohorts, then the possibility of influencing postoperative renal function is on the table. If postoperative renal failure can be predicted, then measures other than maintaining an elevated mean blood pressure, maximizing postoperative cardiac output, achieving an adequate volume status, and avoiding nephrotoxic agents can be instituted. 
Menasché and colleagues ${ }^{9}$ have shown that administering deferoxamine (an iron binder) during CPB can reduce production of damaging free radicals. Choi and colleagues $^{7}$ suggested deferoxamine cartridges during CPB and ferroptosis inhibitors postoperatively to decrease renal insufficiency.

Iron Man, in the movie Iron Man 2, blurted, "Sometimes you have to run before you can walk." ${ }^{10}$ Perhaps cardiac surgeons should use kidney-preserving technology that decreases iron levels during cardiopulmonary bypass before all the nuances of iron physiology during and after cardiopulmonary bypass are evident.

\section{References}

1. Mehaffey JH, Hawkins RB, Byler M, Charles EJ, Fonner C, Kron I, et al. Virginia cardiac services quality initiative. Cost of individual complications following coronary artery bypass grafting. J Thorac Cardiovasc Surg. 2018; 155:875-82.e1.

2. Kramer RS, Herron CR, Groom RC, Brown JR. Acute kidney injury subsequent to cardiac surgery. J Extra Corpor Technol. 2015;47:16-28.
3. Bouma HR, Mungroop HE, De Geus AF, Huisman DD, Nijsten MWN, Mariani MA, et al. Acute kidney injury classification underestimates long-term mortality after cardiac valve operations. Ann Thorac Surg. 2018;106:92-8.

4. Albert C, Albert A, Kube J, Bellomo R, Wettersten N, Kuppe H, et al. Urinary biomarkers may provide prognostic information for subclinical acute kidney injury after cardiac surgery. J Thorac Cardiovasc Surg. 2018;155:2441-52.e13.

5. Moledina DG, Isguven S, McArthur E, Thiessen-Philbrook H, Garg AX. Translational research investigating biomarker endpoints in acute kidney injury (TRIBE-AKI) consortium, Shlipak M, et al. Plasma monocyte chemotactic protein-1 is associated with acute kidney injury and death after cardiac operation. Ann Thorac Surg. 2017;104:613-20.

6. van Swelm RP, Wetzels JF, Verweij VG, Laarakkers CM, Pertijs JC, van der Wijst J, et al. Renal handling of circulating and renal-synthesized hepcidin and its protective effects against hemoglobin-mediated kidney injury. J Am Soc Nephrol. 2016;27:2720-32.

7. Choi N, Whitlock R, Klassen J, Zappitelli M, Arora RC, Rigatto C, et al. Early intraoperative iron-binding proteins are associated with acute kidney injury after cardiac surgery. J Thorac Cardiovasc Surg. 2019;157:287-97.e2.

8. Thakar CV, Arrigain S, Worley S, Yared JP, Paganini EP. A clinical score to predict acute renal failure after cardiac surgery. J Am Soc Nephrol. 2005;16:162-8.

9. Menasché P, Pasquier C, Bellucci S, Lorente P, Jaillon P, Piwnica A. Deferoxamine reduces neutrophil-mediated free radical production during cardiopulmonary bypass in man. J Thorac Cardiovasc Surg. 1988;96:582-9.

10. Iron Man 2 [film]. Hollywood: Paramount Pictures; 2010. 